\title{
Electronic Cigarette Use in US Adults at Risk for or with COPD: Analysis from Two Observational Cohorts
}

\author{
Russell P. Bowler, MD, PhD ${ }^{1,2}$, Nadia N Hansel, MD³, Sean Jacobson, BS 2 , R. Graham Barr, MD4, \\ Barry J. Make, MD², MeiLan K. Han, MD ${ }^{5,6}$, Wanda K O'Neal, PhD', Elizabeth C Oelsner, MD", \\ Richard Casaburi, $M D^{8}$, Igor Barjaktarevic, $M D^{9}$, Chris Cooper, MD , Marilyn Foreman, $\mathrm{MD}^{10}$, \\ Robert A. Wise, MD ${ }^{3}$, Dawn L. DeMeo, MD ${ }^{17}$, Edwin K. Silverman, MD, PhD ${ }^{17}$, William Bailey, MD ${ }^{12}$, \\ Kathleen F. Harrington, $\mathrm{MD}^{12}$, Prescott G. Woodruff, $\mathrm{MD}^{13}$, and M. Bradley Drummond, $\mathrm{MD}^{7}$ for \\ COPDGene and SPIROMICS Investigators
}

\begin{abstract}
'University of Colorado Anschutz Medical Campus, Aurora, CO, USA; ${ }^{2}$ National Jewish Health, Denver, CO, USA; ${ }^{3}$ Division of Pulmonary and Critical Care Medicine, Johns Hopkins University School of Medicine, Baltimore, MD, USA; ${ }^{4}$ Departments of Medicine and Epidemiology, Columbia University Medical Center, New York, NY, USA; ${ }^{5}$ Division of Pulmonany and Critical Care Medicine, University of Michigan Health System, Ann Arbor, MI, USA; ${ }^{6}$ VA Ann Arbor Healthcare System, Ann Arbor, MI, USA; 7 Department of Medicine, Marsico Lung Institute/Cystic Fibrosis Research Center, University of North Carolina at Chapel Hill, Chapel Hill, North Carolina, USA; ${ }^{8}$ Rehabilitation Clinical Trials Center, Los Angeles Biomedical Research Institute at Harbor-UCLA Medical Center, Torrance, CA, USA; ${ }^{9}$ Division of Pulmonary and Critical Care Medicine, Department of Medicine, David Geffen School of Medicine, University of California Los Angeles, California, Los Angeles, USA; ${ }^{10}$ Department of Medicine, Morehouse School of Medicine, Atlanta, GA, USA; " Channing Division of Network Medicine, Department of Medicine, Brigham and Women's Hospital, Harvard Medical School, Boston, MA, USA; ${ }^{2}$ Division of Pulmonary, Allergy and Critical Care Medicine, University of Alabama at Birmingham, Birmingham, AL, USA; ${ }^{13}$ Division of Pulmonary, Critical Care, Sleep and Allergy, Department of Medicine and Cardiovascular Research Institute, University of California San Francisco, School of Medicine, San Francisco, CA, USA.
\end{abstract}

BACKGROUND: Electronic cigarettes (e-cigarettes) are battery-operated nicotine-delivery devices used by some smokers as a cessation tool as well as by never smokers. OBJECTIVE: To determine the usage of e-cigarettes in older adults at risk for or with chronic obstructive pulmonary disease (COPD).

DESIGN: Prospective cohorts.

PARTICIPANTS: COPDGene $(N=3536)$ and SPIROMICS $(N=1060)$ subjects who were current or former smokers aged 45-80.

MAIN MEASURES: Participants were surveyed to determine whether e-cigarette use was associated with longitudinal changes in COPD progression or smoking habits. KEY RESULTS: From 2010 to 2016, participants who had ever used e-cigarettes steadily increased to $12-16 \%$, but from 2014 to 2016 current use was stable at $~ 5 \%$. Ecigarette use in African-Americans (AA) and whites was similar; however, AA were 1.8-2.9 times as likely to use menthol-flavored e-cigarettes. Current e-cigarette and conventional cigarette users had higher nicotine dependence and consumed more nicotine than those who smoked only conventional cigarettes. E-cigarette users had a heavier conventional cigarette smoking history and worse respiratory health, were less likely to reduce or quit conventional cigarette smoking, had higher nicotine dependence, and were more likely to report chronic bronchitis and exacerbations. Ever e-cigarette users had more rapid decline in lung function, but this trend did not

Electronic supplementary material The online version of this article (doi:10.1007/s11606-017-4150-7) contains supplementary material, which is available to authorized users.

Received April 27, 2017

Revised June 28, 2017

Accepted July 21, 2017

Published online September 7, 2017 persist after adjustment for persistent conventional cigarette smoking.

CONCLUSIONS: E-cigarette use, which is common in adults with or at risk for COPD, was associated with worse pulmonary-related health outcomes, but not with cessation of smoking conventional cigarettes. Although this was an observational study, we find no evidence supporting the use of e-cigarettes as a harm reduction strategy among current smokers with or at risk for COPD.

KEY WORDS: COPD; electronic cigarette; lung function; tobacco.

J Gen Intern Med 32(12): 1315-22

DOI: $10.1007 / \mathrm{s} 11606-017-4150-7$

(c) Society of General Internal Medicine 2017

\section{INTRODUCTION}

Electronic cigarettes (e-cigarettes) are nicotine-delivery devices that use a heating element to vaporize a stabilizing compound containing nicotine, flavors, and other bulk additives. This process generates a vapor that visually appears similar to smoke. E-cigarettes have been adopted by some conventional cigarette (tobacco leaf) users as a perceived safer alternative, as these devices deliver nicotine in a manner simulating conventional cigarettes, but without inhalational exposure to burned tobacco plant material. This harmreduction hypothesis has been supported by studies of ecigarette vapors, which have shown lower toxicant levels per puff compared to tobacco smoke. ${ }^{1}$ Long-term data on the harms from e-cigarette use are not currently available. Studies have yielded conflicting information on the effect of ecigarettes on conventional cigarette reduction and cessation, ${ }^{2-6}$ and a recent meta-analysis suggests that they may 
impede efforts to quit. ${ }^{7}$ Additional research is needed to clearly weigh the risk/benefit balance of e-cigarette use.

The prevalence of e-cigarette use has been increasing among adolescents and adults in both the US $^{8}$ and Europe. ${ }^{9}$ In adults, the highest prevalence is in current conventional cigarette smokers, of whom $31 \%$ report having tried electronic cigarettes. ${ }^{9}$ There are few studies documenting use trends in older smokers and none in individuals with established smoking-induced lung disease such as chronic obstructive pulmonary disease (COPD). Additionally, there are few publications exploring usage patterns by race, flavor choice preferences in adults, and how e-cigarette use relates to wholebody nicotine metabolite burden. The current study collected e-cigarette usage data from two large cohorts of adult current and former smokers with and without lung disease: Genetic Epidemiology of COPD (COPDGene) and Subpopulations and Intermediate Outcome Measures in COPD Study (SPIROMICS). We determined whether e-cigarettes prevalence was increasing in older adults, whether usage was associated with respiratory symptoms or disease progression, and whether e-cigarettes were associated with self-reported reduction in the use of conventional cigarettes.

\section{METHODS}

\section{Study Populations}

The NIH-sponsored multicenter COPDGene study (ClinicalTrials.gov Identifier: NCT01969344) includes 10,294 subjects enrolled from 2008 to 2011 who were aged 45-80, self-reported non-Hispanic white or African-American, and with a history of at least 10 pack-years of conventional cigarette smoking $(N=10,192)$ or no conventional cigarette smoking ( $\leq 1$ pack-year lifetime; $N=102) .{ }^{10}$

The NIH-sponsored multicenter SPIROMICS (ClinicalTrials.gov Identifier: NCT01969344) is a cohort study ${ }^{11}$ that enrolled 2982 subjects between November 2011 and January 2015 . Inclusion criteria included age $40-80$ years and at least 20 pack-years of conventional cigarette smoking $(N=2780)$ or never tobacco smokers $(N=202)$. For COPDGene and SPIROMICS, the institutional review boards at all participating sites approved the study protocol, and study participants provided written informed consent.

\section{Conventional and E-Cigarette Data Collection}

COPDGene and SPIROMICS introduced similar e-cigarette questionnaires (which can be download at http://www. copdgene.org/phase-2-study-documents-0 and https://www2. cscc.unc.edu/spiromics/forms-current) in 2014. Data reported here include results from 3536 consecutive COPDGene subjects who completed the questionnaire at the time of the 5-year follow-up visit (2014-2016) and 1060 consecutive SPIROMICS subjects who completed the questionnaire at the time of enrollment (2014-2015). Subjects who answered "yes" to whether they sill smoked e-cigarettes were considered current users. Subjects were asked when they started, whether their e-cigarettes were flavored, and how often they used them, as well as questions on motivation for use and whether e-cigarette use impacted conventional cigarette smoking. In COPDGene, conventional cigarette smoking was assessed at both baseline and 5-year follow-up visit. In SPIROMICS there was not a sufficient number of subjects who had both long-term follow-up visits ( $>1$ year) and ecigarette questionnaire data; thus these subjects were included only in the cross-sectional analysis.

\section{Clinical Data and Definitions}

Full details on COPDGene and SPIROMICS data collection have been described previously. ${ }^{10,}{ }^{11}$ In both cohorts, COPD was defined as post-bronchodilator ratio of forced expiratory volume in one second $\left(\mathrm{FEV}_{1}\right)$ to forced expiratory volume $(\mathrm{FVC})<0.70$. The Global Initiative for Chronic Obstructive Lung Disease (GOLD) criteria $^{12}$ were used to assess COPD spirometric severity (i.e. GOLD stages $1-4$ ). Current or exsmokers at risk for COPD but without spirometric evidence of airflow obstruction $\left(\mathrm{FEV}_{1} / \mathrm{FVC} \geq 0.70\right)$ were classified as GOLD 0. Subjects with $\mathrm{FEV}_{1} / \mathrm{FVC} \geq 0.70$ and $\mathrm{FEV}_{1}<80 \%$ were classified as preserved ratio impaired spirometry (PRISm) ${ }^{13}$ In COPDGene, spirometric measurements were made at baseline and 5-year follow-up visits, and the rate of decline in lung function was annualized. The St. George's Respiratory Questionnaire (SGRQ) was used to capture health-related quality of life. ${ }^{14}$ Dyspnea was measured using the modified Medical Research Council (mMRC) score. ${ }^{15}$ Chronic bronchitis was defined as the presence of chronic cough and phlegm production for at least 3 months per year for 2 or more consecutive years. ${ }^{16}$ Volumetric computerized tomography (CT) scans were acquired in both cohorts (see Supplemental Appendix for further clinical phenotyping details). Acute exacerbations of respiratory disease (COPD exacerbations) were prospectively assessed every 3 months (SPIROMICS) or every 6 months (COPDGene) after enrollment $\left(\operatorname{see}^{10,11}\right)$. The Fagerström Test for Nicotine Dependence was assessed at baseline in COPDGene subjects who were smoking conventional cigarettes at baseline.

\section{Urinary Nicotine Assessment}

In SPIROMICS, a random urine collection was provided at baseline. Nicotine ( $2 \mathrm{ng} / \mathrm{mL}$ cutoff), three nicotine metabolites [cotinine $(5 \mathrm{ng} / \mathrm{mL}$ cutoff), 3-OH-cotinine ( $50 \mathrm{ng} / \mathrm{mL}$ cutoff), nornicotine $(2 \mathrm{ng} / \mathrm{mL}$ cutoff)], and the tobacco metabolite anabasine ( $3 \mathrm{ng} / \mathrm{mL}$ cutoff)] were measured using quantitative liquid chromatography-tandem mass spectrometry (ARUP Laboratories, Salt Lake City, UT) and adjusted for urinary creatinine (see ${ }^{17}$ for further details on methodology). The presence of nicotine, cotinine, 3-OH-cotinine, or nornicotine is indicative of either combustible or e-cigarette use. Anabasine is only associated with conventional cigarette use. 


\section{Data Sets and Statistical Analysis}

Proportions were compared using chi-square tests. Linear and logistic regression analyses were used for normally distributed continuous and binary outcomes, respectively. Covariates included current conventional cigarette smoking, gender, and race, which were categorical, and pack-years of tobacco use and age, which were continuous. Additional covariates for exacerbations included $\mathrm{FEV}_{1} \%$ predicted, SGRQ, and gastroesophageal reflux disease (GERD). ${ }^{18,19}$ Exacerbations in the year prior to enrollment (retrospective) and during longitudinal follow-up (prospective) were modeled using negative binomial regression with an offset for exposure time and zeroinflated negative binomial (ZINB) regression to account for the excess number of subjects who reported no acute episodes of respiratory disease (see ${ }^{18}$ for a description of modeling exacerbations). Similarly, nicotine metabolites were modeled with ZINB.

\section{RESULTS}

\section{Prevalence of Electronic Cigarette Use Has Increased in Older Adults with and without COPD}

From 2014 to 2016, 3536 subjects participating in COPDGene and 1060 subjects participating in SPIROMICS were asked about their use of e-cigarettes and timing of initiation. Ecigarette use was first reported around 2007, and there was a rapid increase in the cumulative prevalence of ever e-cigarette use in both cohorts starting in 2010 (Fig. 1). A total of 419 $(12 \%)$ subjects in COPDGene and 172 subjects $(16 \%)$ in SPIROMICS reported ever using e-cigarettes. However, only 128 of $3536(4 \%)$ and 55 of 1060 (5\%) were currently using ecigarettes at the time of study visits, with no significant

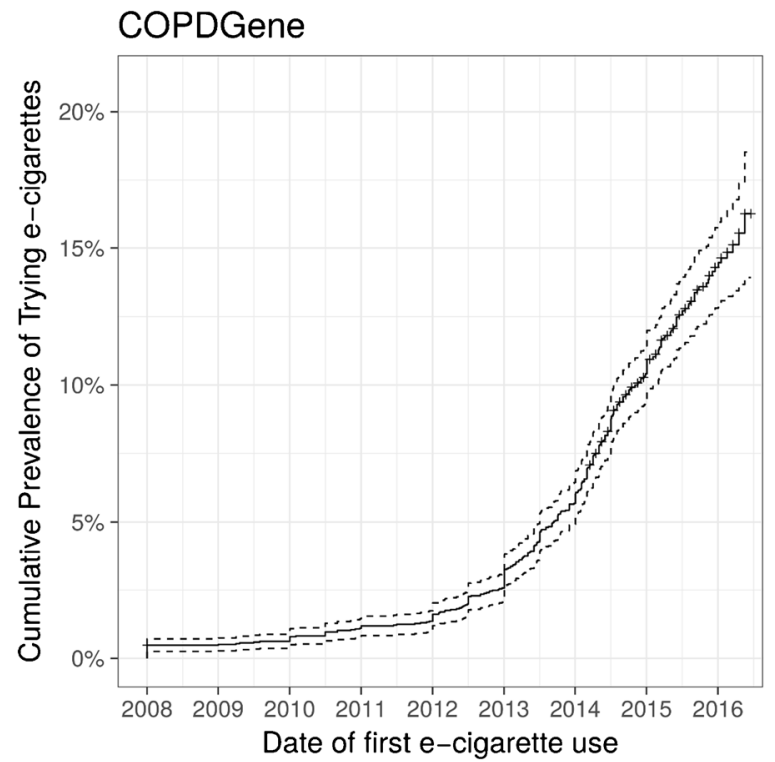

difference in the percentage of subjects currently using ecigarettes at the time of the survey (2014-2016). The duration of e-cigarette use in current smokers was longer in former ecigarette users, but this difference was significant only in the SPIROMICS cohort (Table 1).

Current conventional cigarette smokers in COPDGene and SPIROMICS were 6.1 (95\% CI 4.8-7.7; $p<0.001)$ times and 8.1 (95\% CI 5.4-11.7; $p<0.001$ ) times as likely to have tried e-cigarettes, respectively, as former conventional cigarette smokers. Other characteristics of ever e-cigarette users included younger age, heavier smoking history, worse self-reported health scores (SGRQ and mMRC), less emphysema (measured by lung density) on CT scan, and higher Fagerström Index at baseline enrollment (COPDGene subjects only). There were no consistent gender or race differences between e-cigarette user groups. Subjects with mild, moderate, and severe COPD were just as likely to try and continue to use ecigarettes as those without COPD (Figure S1). Current ecigarette users reported a median use of 3 times per day and 1-3 days per week, but there was a wide variation in usage patterns reported in both current (Figure S2) and former (Figure S3) e-cigarette users.

\section{Flavored E-Cigarettes}

Almost half of COPDGene (42\%) and SPIROMICS (48\%) participants who were ever users of e-cigarettes reported using flavored e-cigarettes, with African-Americans demonstrating a preference for menthol flavor compared to non-Hispanic whites (COPDGene: $70 \%$ vs. $40 \%$, $p<0.001$ and SPIROMICS: $67 \%$ vs. $24 \%, p<0.001$; Fig. 2). There were no significant differences in specific flavor choice by age or gender. However, there was a strong consistent difference in flavor preference between tobacco and e-cigarette users. In COPDGene subjects who

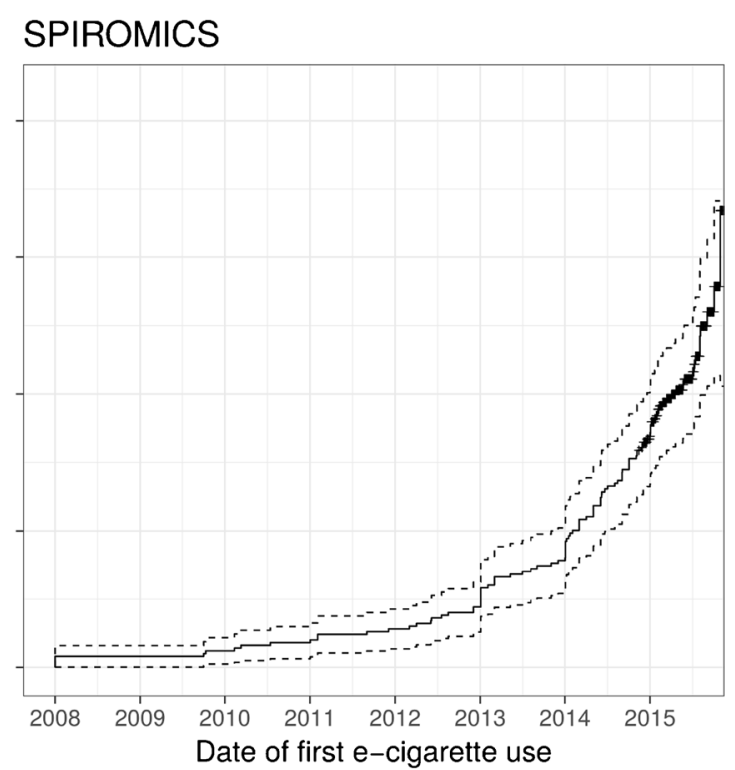

Figure 1 Rising prevalence of ever e-cigarette use in COPDGene (a) and SPIROMICS (b) cohorts. Cumulative prevalence by date of first trying e-cigarettes based on self-reported date of initiating e-cigarette use. 
Table 1 Characteristics of Cohorts

\begin{tabular}{|c|c|c|c|c|c|c|}
\hline \multirow[b]{2}{*}{ E-cigarette use } & \multicolumn{3}{|c|}{ COPDGene $(N=3435)$} & \multicolumn{3}{|c|}{ SPIROMICS $(N=1060)$} \\
\hline & $\begin{array}{l}\text { Never } \\
(N=3117)\end{array}$ & $\begin{array}{l}\text { Current } \\
(N=127)\end{array}$ & $\begin{array}{l}\text { Former } \\
(N=291)\end{array}$ & $\begin{array}{l}\text { Never } \\
(N=888)\end{array}$ & $\begin{array}{l}\text { Current } \\
(N=55)\end{array}$ & $\begin{array}{l}\text { Former } \\
(N=117)\end{array}$ \\
\hline Age & $61 \pm 9$ & $57 \pm 7 * * *$ & $55 \pm 7 * * *+4$ & $64 \pm 9$ & $60 \pm 9 * * *$ & $59 \pm 9 * * *$ \\
\hline Gender ( $\%$ male $)$ & $51 \%$ & $41 \% *$ & $43 \% * *$ & $54 \%$ & $55 \%$ & $44 \%$ \\
\hline BMI & $29 \pm 6$ & $28 \pm 6$ & $29 \pm 6$ & $28 \pm 5$ & $27 \pm 5$ & $28 \pm 5$ \\
\hline Never conventional cig. smoker & $2 \%$ & $0 \%$ & $0 \%$ & $6 \%$ & $0 \% * * *$ & $1.7 \%$ tt \\
\hline Current conventional cig. smoker & $41 \%$ & $92 \% * * *$ & $86 \% * * *$ & $27 \%$ & $75 \% * * *$ & $73 \% * * * 1+4$ \\
\hline Pack-years & $42 \pm 24$ & $49 \pm 23 * *$ & $42 \pm 21^{*+*}$ & $46 \pm 31$ & $52 \pm 39$ & $44 \pm 17$ \\
\hline Years using e-cigarettes & - & $2.0 \pm 4.3$ & $0.6(3.8)$ & - & $3.9 \pm 9.6$ & $0.5 \pm 2.3^{\ddagger}$ \\
\hline $\mathrm{FEV}_{1}(\mathrm{~L})$ & $2.3 \pm 0.9$ & $2.3 \pm 0.8$ & $2.4 \pm 0.8$ & $2.1 \pm 0.9$ & $2.3 \pm 0.9$ & $2.3 \pm 0.9$ \\
\hline Fagerström Index & $4.58 \pm 2.39$ & $5.04 \pm 2.38^{*}$ & $5.02 \pm 2.24 * *$ & & & \\
\hline Hx smoking \& normal spirometry & $45 \%$ & $43 \%$ & $46 \%$ & $31 \%$ & $33 \%$ & $37 \%$ \\
\hline COPD (GOLD 1, 2) & $27 \%$ & $31 \%$ & $30 \%$ & $41 \%$ & $51 \%$ & $47 \%$ \\
\hline COPD (GOLD 3, 4) & $13 \%$ & $13 \%$ & $10 \%$ & $20 \%$ & $16 \%$ & $15 \%$ \\
\hline PRISm & $12 \%$ & $13 \%$ & $13 \%$ & - & - & - \\
\hline Emphysema baseline (LAA $-950 \mathrm{HU}$ ) & $5 \% \pm 8 \%$ & $4 \% \pm 5 \% * *$ & $4 \% \pm 7 \% * *$ & $8 \% \pm 10 \%$ & $5 \% \pm 7 \% *$ & $5 \% \pm 9 \% * *$ \\
\hline St. George's Respiratory Questionnaire & $23 \pm 21$ & $28 \pm 22^{*}$ & $26 \pm 22 *$ & $32 \pm 21$ & $36 \pm 23$ & $37 \pm 22 *$ \\
\hline Decline in $\mathrm{FEV}_{1}(\mathrm{~mL} / \mathrm{yr})$ & $32 \pm 55$ & $39 \pm 45$ & $45 \pm 66$ & $49 \pm 159$ & $68 \pm 182$ & $108 \pm 185$ \\
\hline Chronic bronchitis & $14 \%$ & $34 \% * * *$ & $25 \% * * *$ & $19 \%$ & $20 \%$ & $22 \%$ \\
\hline
\end{tabular}

Shown are \% or mean $\pm S D ; F E V_{l}=$ forced expiratory volume at one second; PRISm = preserved ratio, impaired spirometry $\left(F E V_{l} / F V C>0.7 \&\right.$ $F E V_{1} \%<80 \%$ ); 5-year decline in FEV ${ }_{1}$ was available for all COPDGene subjects, but only at 1 year and only for 30\% of SPIROMICS subjects. $* P<0.05, * * P<0.01, * * * P<0.001$, compared to never e-cigarette users, ${ }^{*} P<0.05,{ }^{* t} P<0.01,{ }^{* t+} P<0.001$, compared to current e-cigarette users

used e-cigarettes, 96\% who smoked non-menthol conventional cigarettes at baseline did not use menthol-flavored e-cigarettes in the next 5 years, whereas $51 \%$ of subjects who smoked menthol conventional cigarettes at baseline reported trying menthol-flavored e-cigarettes within the following 5 years $(p<0.001)$.

\section{Dual Use of E-Cigarettes and Conventional Cigarettes}

The majority of individuals (93\% in COPDGene and $87 \%$ in SPIROMICS) reported starting e-cigarettes to cut down or stop smoking regular conventional cigarettes, and $85 \%$ in COPDGene and $81 \%$ in SPIROMICS stated that they started e-cigarettes in order to improve their health. Although $47 \%$ of COPDGene subjects who used e-cigarettes thought they reduced the number of conventional cigarettes they smoked, ever using e-cigarettes during a 5-year longitudinal follow-up period was associated with smoking an average of two additional conventional cigarettes per day at 5-year follow-up compared to baseline $(p<0.001)$; however, this difference was no longer significant after adjusting for age, race, gender, and number of cigarettes smoked at baseline.

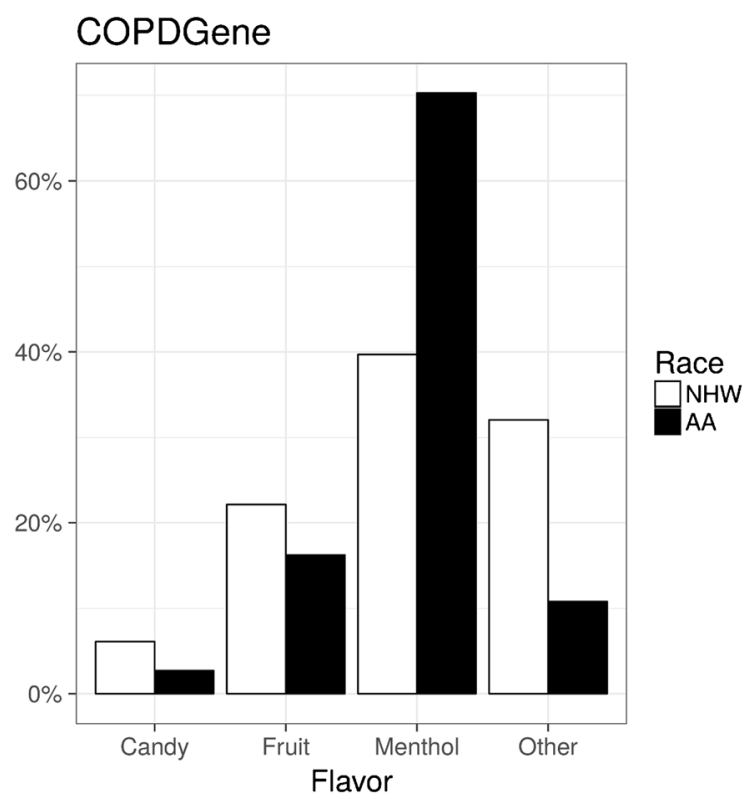

\section{SPIROMICS}

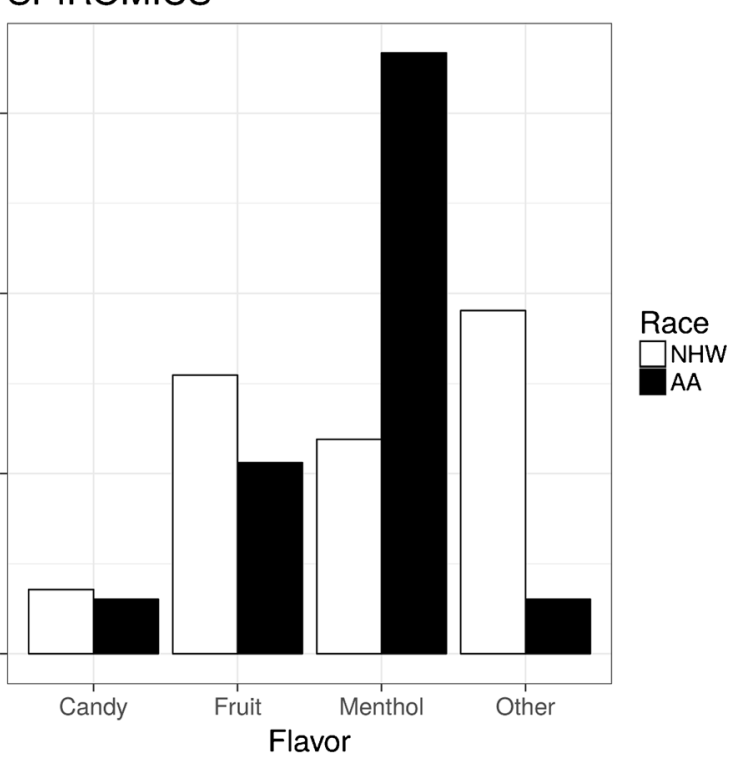

Figure 2 African-Americans have a strong preference for menthol flavor compared to non-Hispanic Whites. Data shown are flavor preferences for those who use flavored e-cigarettes from COPDGene (a) and SPIROMICS (b) cohorts. NHW: non-Hispanic whites, AA: African- 
It is concerning that 20 of 53 former conventional cigarette smokers at the baseline exam who reported use of e-cigarettes in the next 5 years had resumed tobacco smoking at the 5-year follow-up, versus 64 of 1837 who did not use e-cigarettes $(p<0.001)$, suggesting that e-cigarette users were $16.8(95 \%$ CI $9.1-30.9 ; p<0.001)$ times as likely to have resumed conventional cigarette smoking. Similarly, for those who were current conventional cigarette smokers at baseline and who reported ever using e-cigarettes during the 5-year follow-up, the odds of having quit conventional cigarettes at their followup visit were 0.7 times lower (95\% CI $0.5-0.9 ; p=0.02)$; however, after adjusting for the Fagerström score at the baseline visit, the significance of ever using e-cigarettes relative to quitting conventional cigarettes was 0.8 (95\% CI 0.57-1.02; $p=0.06)$. Indeed, a one-point increase in the Fagerström score at baseline was associated with a reduction of 0.86 (95\% CI $0.82-0.90 ; p<0.001)$ in the odds of quitting smoking, even after adjusting for e-cigarette use. Thus, nicotine dependence seems to account for some of the dual usage of conventional and e-cigarettes and the failure to quit smoking.

To further investigate whether current e-cigarette use was associated with less consumption of tobacco or nicotine, in SPIROMICS we examined both tobacco-specific urinary metabolites (anabasine) and urinary nicotine metabolites that are present with both conventional and ecigarette use (Fig. 3). Urine anabasine levels in current conventional cigarette smokers were similar among current, former, and never e-cigarette users (Fig. 3a), suggesting that they were smoking similar numbers of conventional cigarettes. However, current e-cigarette users had higher urine levels of the nicotine metabolite cotinine (Fig. 3b) as well as three other nicotine metabolites (Figure S4), suggesting that they were consuming more

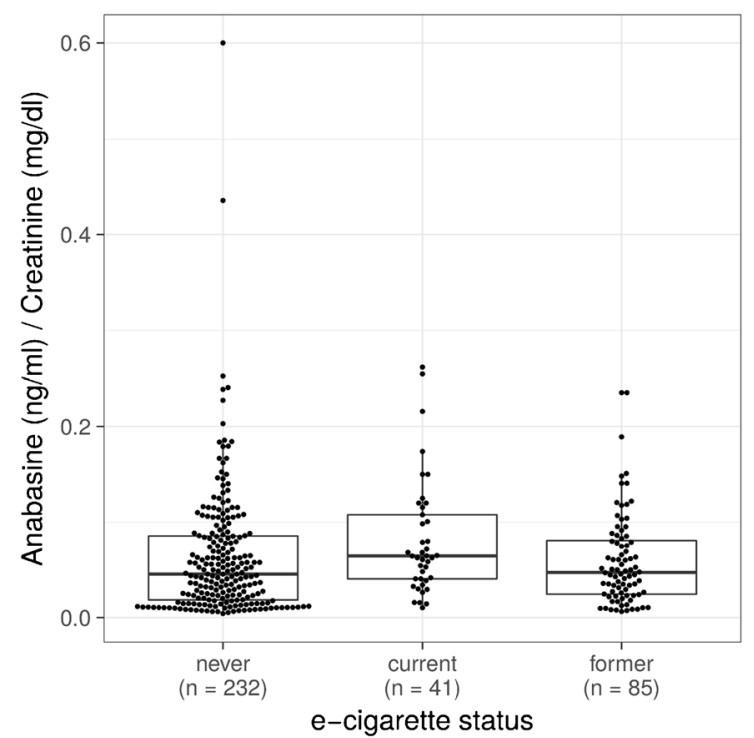

total nicotine (e-cigarettes + conventional cigarettes) than those not currently using e-cigarettes. The Fagerström score was not assessed in the SPIROMICS cohort, so we were unable to assess what influence nicotine dependence had on urinary metabolites.

\section{Pulmonary Disease in E-Cigarette Users}

A history of ever e-cigarette use was associated with several adverse COPD outcomes in the COPDGene cohort. In particular, ever using e-cigarettes was associated with $8 \pm 2 \%$ increased prevalence of chronic bronchitis, even after adjusting for current tobacco smoking, age, race, gender, and pack-years $(p<0.001)$. Emphysema at baseline, as assessed by density measurements, was lower in the e-cigarette users, but this difference was no longer significant when adjusting for current tobacco smoking and other covariates. A history of ever using e-cigarettes was significantly predictive of COPD exacerbations in COPDGene ( $p=0.01)$, even after adjusting for baseline history of exacerbations, age, gender, current tobacco smoking, FEV 1 , GERD, and SGRQ (Table S1). There were not sufficient prospective exacerbation events to evaluate this association in the SPIROMICS cohort; however, ever using ecigarettes was associated with reported exacerbations in the year prior to enrollment $(p=0.04)$.

In the COPDGene cohort, subjects who ever used ecigarettes were more likely to have progression of lung disease (defined by worsening of GOLD stage) after 5 years (Fig. 4; $p<0.001)$ and a more rapid decline in lung function $\left(\mathrm{FEV}_{1}\right)$ than never users (43 mL/year vs. $34 \mathrm{~mL} /$ year; $p=0.003$ ). Worsening GOLD stage and more rapid decline in lung function were no longer significant after adjusting for age, race, gender, and current use of conventional cigarettes.

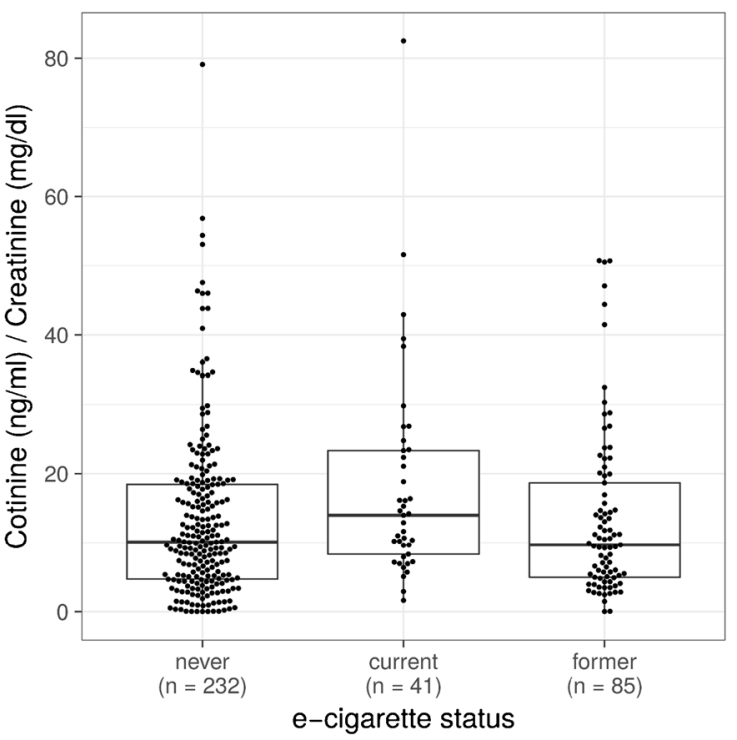

Figure 3 In current conventional cigarette smokers, current e-cigarette use is associated with higher nicotine consumption, but not lower tobacco consumption. (a) In conventional cigarette smokers, there is no difference in urinary anabasine (indicative of tobacco use) based on ecigarette status ( $p=$ not significant). (b) Dual current e-cigarette and current conventional cigarette users have higher levels of cotinine (indicative of any nicotine ingestion) in the urine after adjustment for age and gender $(p<0.001)$ compared to current conventional smokers who are former or never e cigarette users. Boxes represent 25 th, 50 th, and 75 th percentiles. 


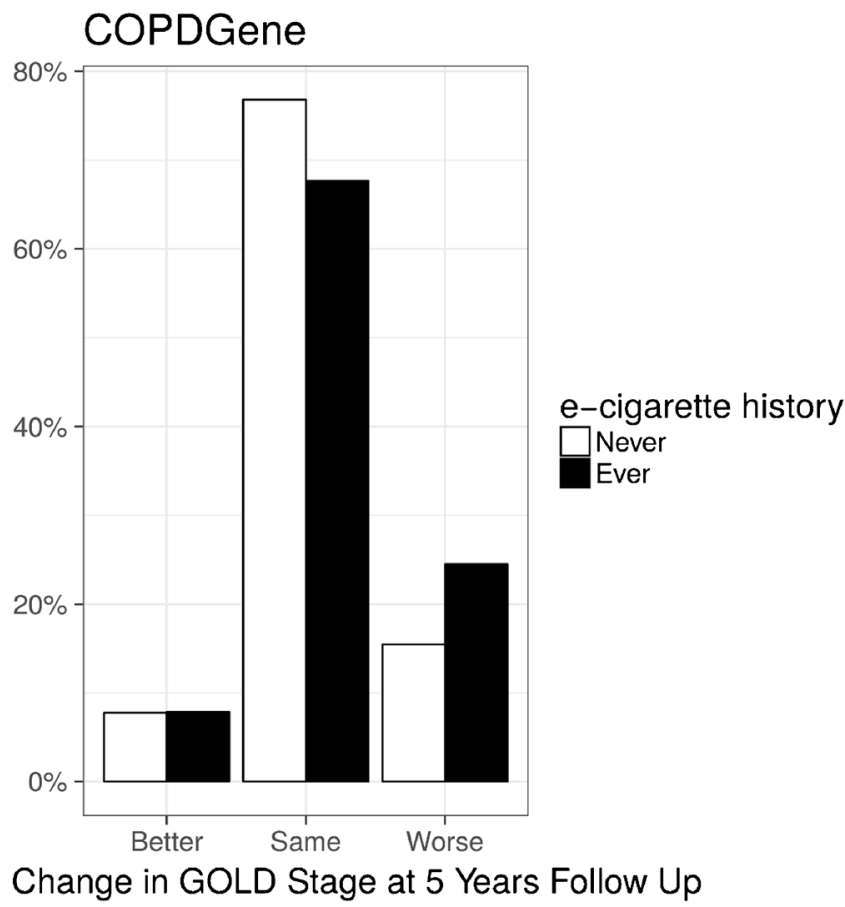

Figure 4 E-cigarette use is associated with a higher percentage of worsening lung function (increase in GOLD stage) over a 5-year period in the COPDGene cohort.

\section{DISCUSSION}

The popular press and scientific e-cigarette literature in both Europe ${ }^{9}$ and the US $^{20}$ have focused on the rising prevalence of use in adolescents and young adults who are generally healthy. This study describes e-cigarette use in two large cohorts of current and former smokers (SPIROMICS and COPDGene) and is the first to include older current and former conventional cigarette smokers with and without COPD. Similar to publications that focus on younger adults and those without lung disease, we demonstrate that, starting around 2010, there has been a rapid rise in the prevalence of smokers trying e-cigarettes among older adults with or at risk for COPD. Current use among this population stabilized at $\sim 5 \%$, suggesting that many of these smokers tried but did not continue to use ecigarettes; however, a significant difference between older and younger adults is that only $1 \%$ of older adult never smokers try e-cigarettes, compared to $10-40 \%$ of $18-24$ year-old never smokers. ${ }^{20,21}$

Safety and harm reduction are cited as rationales for ecigarette use, ${ }^{22}$ but our study finds no evidence that ecigarette users had less progression of chronic lung disease. Instead, we find that e-cigarette use was associated with an increased prevalence of chronic bronchitis and COPD exacerbations and some evidence of more rapid decline in lung function in e-cigarette users, even after adjusting for increased tobacco smoking associated with e-cigarettes. While these data may suggest that ecigarettes directly lead to harm, the observational nature of this cohort precludes causal inference between e- cigarettes and adverse pulmonary outcomes. Reverse causation, whereby individuals who develop respiratory symptoms from tobacco use may switch to e-cigarettes, may also explain these observations. Nevertheless, there is no evidence of benefit of e-cigarettes in this population. Despite experimental evidence for airway toxicity, ${ }^{23}$ we found mixed evidence that e-cigarette use was associated with either improvement in or worsening of airway obstruction, especially when adjusting for conventional cigarette smoking.

A purported rationale for e-cigarettes is that they help reduce conventional cigarette smoking and improve smoking cessation rates. We found no evidence that ecigarette use in this observational study was associated with either self-reported cessation or reduction in conventional cigarette use. Ever using e-cigarettes during 5 years of longitudinal follow-up was associated with an increase of two cigarettes per day at 5-year follow-up compared to baseline. Moreover, urinary metabolite analysis confirmed two observations: 1) current e-cigarette users had similar amounts of the conventional cigarette metabolite anabasine, suggesting no decrease in combustible cigarettes, and 2) current e-cigarette users had more cotinine (marker for total nicotine ingestion) in their urine, suggesting an increase in combined conventional and ecigarette use. The observation that SPIROMICS ecigarette users consumed more nicotine is supported by the finding that COPDGene e-cigarette users had higher nicotine dependence before they tried e-cigarettes. This nicotine dependence explains in part why e-cigarette users may be more likely to fail at smoking cessation, and is consistent with several recently published randomized controlled trials (RCTs) demonstrating no difference in cessation rates with e-cigarette use. ${ }^{2-5}$ While these RCTs failed to demonstrate an effect on cessation rates, however, several reported an association between e-cigarette use and reduced conventional cigarette use. In our study, we found no significant correlation between the frequency of e-cigarette use and the frequency of tobacco cigarette use.

Flavor has historically played a prominent role in tobacco advertising, and the strong preference for menthol in AfricanAmerican smokers ${ }^{24}$ suggests that this marketing has carried over to e-cigarettes. Surprisingly, older adults also frequently used candy and fruit flavors in their e-cigarettes. The use of flavors may lead to more enjoyment, better taste, and food craving, ${ }^{25}$ but there is concern that some flavor additives, such as benzaldehyde, common in cherry-flavored liquid, may cause increased airway irritation. ${ }^{26}$ Other flavors also contain diacetyl, which has been associated with bronchiolitis obliterans, or "popcorn workers lung." 27 Although we found insufficient evidence that flavors were associated with lung disease, our studies are underpowered for looking at these associations.

The major strengths of this study are the large number of older adults with and without COPD, the longitudinal 
follow-up, and the biochemical documentation of smoking and vaping behavior. A major limitation is the observational nature of the study. An alternative explanation for these findings may be that smokers with more comorbidities, symptoms, and disease progression are both more likely to try e-cigarettes and to fail at quitting smoking. The slightly higher Fagerström Index in COPDGene ecigarette users and higher nicotine metabolites in the urine of SPIROMICS e-cigarette users does suggest that future e-cigarette users are more prone to nicotine physical dependence; however, results were similar when adjusting for the Fagerström Index. Although anabasine has been detected in e-cigarette fluids, ${ }^{28}$ the levels are generally considerably lower than those from tobacco cigarette vapors and fluids. It is unlikely that e-cigarette use contributed significantly to the anabasine levels in our measurements. The high nicotine dependence and frequent dual usage may explain why we did not observe significant harm reduction associated with e-cigarette use. Since this is not an RCT, one cannot definitely conclude whether ecigarette use leads to harm or harm reduction.

In summary, we show that e-cigarette use is increasing in prevalence in older adults with a history of cigarette smoking. We found that adults also use menthol, fruit, and candy flavors, and there are racial differences in flavor preference. While experimental studies may suggest that e-cigarettes have lower amounts of harmful substances, our findings do not support a reduction in harm through the use of e-cigarettes, and may even suggest higher nicotine exposure, higher risk of exacerbations, and greater loss of lung function.

\section{Acknowledgements:}

\section{SPIROMICS:}

The authors thank the SPIROMICS participants and participating physicians, investigators, and staff for making this research possible. More information about the study and how to access SPIROMICS data is available at www.spiromics.org. We would like to acknowledge the following current and former investigators of the SPIROMICS sites and reading centers: Neil E Alexis, PhD; Wayne H Anderson, $P h D ; R$ Graham Barr, MD, DrPH; Eugene R Bleecker, MD; Richard C Boucher MD; Russell P Bowler, MD, PhD; Elizabeth E Carretta, MPH; Stephanie A Christenson, MD; Alejandro P Comellas, MD; Christopher B Cooper, $M D, P h D$; David J Couper, PhD; Gerard J Criner, MD; Ronald G Crystal, MD; Jeffrey L Curtis, MD; Claire M Doerschuk, MD; Mark T Dransfield, MD; Christine M Freeman, PhD; MeiLan K Han, MD, MS; Nadia N Hansel, MD, MPH; Annette T Hastie, PhD; Eric A Hoffman, $P h D$; Robert J Kaner, $M D$; Richard E Kanner, $M D$; Eric C Kleerup, $M D$ Jerry A Krishnan, $M D$, PhD; Lisa M LaVange, PhD; Stephen C Lazarus, MD; Fernando J Martinez, MD, MS; Deborah A Meyers, PhD; John D Newell Jr., MD; Elizabeth C Oelsner, MD, MPH; Wanda K O'Neal, PhD; Robert Paine, III, MD; Nirupama Putcha, MD, MHS; Stephen I. Rennard, MD; Donald P Tashkin, MD; Mary Beth Scholand, $M D$; J Michael Wells, MD; Robert A Wise, MD; and Prescott G Woodruff, MD, MPH. The project officers from the Lung Division of the National Heart, Lung, and Blood Institute were Lisa Postow, PhD, and Thomas Croxton, $\mathrm{PhD}, \mathrm{MD}$.

COPDGene:: COPDGene ${ }^{\circledR}$ Investigators - Core Units Administrative Center: James D. Crapo, MD (PI); Ed win K. Silverman, $M D, P h D(P I)$; Barry J. Make, MD; Elizabeth A. Regan, $M D, P h D$.
Genetic Analysis Center: Terri Beaty, PhD; Ferdouse Begum, PhD; Robert Busch, MD; Peter J. Castaldi, MD, MSc; Michael Cho, MD; Dawn L. DeMeo, MD, MPH; Adel R. Boueiz, MD; Marilyn G. Foreman, MD, MS; Eitan Halper-Stromberg; Nadia N. Hansel, MD, MPH; Megan E. Hardin, MD; Lystra P. Hayden, MD, MMSc; Craig P. Hersh, MD, MPH; Jacqueline Hetmanski, MS, MPH; Brian D. Hobbs, MD; John E. Hokanson, MPH, $\mathrm{PhD}$; Nan Laird, PhD; Christoph Lange, PhD; Sharon M. Lutz, PhD; MerryLynn McDonald, PhD; Margaret M. Parker, PhD; Dandi Qiao, PhD; Elizabeth A. Regan, $M D$, PhD; Stephanie Santorico, PhD; Edwin K. Silverman, $M D$, PhD; Emily S. Wan, MD; Sungho Won.

Imaging Center: Mustafa Al Qaisi, MD; Harvey O. Coxson, PhD; Teresa Gray; MeiLan K. Han, MD, MS; Eric A. Hoffman, PhD; Stephen Humphries, PhD; Francine L. Jacobson, MD, MPH; Philip F. Judy, PhD; Ella A. Kazerooni, MD; Alex Kluiber; David A. Lynch, MB; John D. Newell, Jr., MD; Elizabeth A. Regan, $M D, P h D$; James C. Ross, $P h D$; Raul San Jose Estepar, PhD; Joyce Schroeder, MD; Jered Sieren; Douglas Stinson; Berend C. Stoel, PhD; Juerg Tschirren, PhD; Edwin Van Beek, MD, PhD; Bram van Ginneken, PhD; Eva van Rikxoort, PhD;

George Washko, MD; Carla G. Wilson, MS.

PFT QA Center, Salt Lake City, UT: Robert Jensen, PhD.

Data Coordinating Center and Biostatistics, National Jewish Health, Denver, CO: Douglas Everett, PhD; Jim Crooks, PhD; Camille Moore, PhD; Matt Strand, PhD; Carla G. Wilson, MS.

Epidemiology Core, University of Colorado Anschutz Medical Campus, Aurora, CO: John E. Hokanson, MPH, PhD; John Hughes, PhD; Gregory Kinney, MPH, PhD; Sharon M. Lutz, PhD; Katherine Pratte, MSPH;

Kendra A. Young, PhD.

COPDGene $e^{\infty}$ Investigators - Clinical Centers

Ann Arbor VA: Jeffrey L. Curtis, MD; Carlos H. Martinez, MD, MPH; Perry G. Pernicano, MD.

Baylor College of Medicine, Houston, TX: Nicola Hanania, MD, MS; Philip Alapat, MD; Mustafa Atik, MD; Venkata Bandi, MD; Aladin Boriek, PhD; Kalpatha Guntupalli, MD; Elizabeth Guy, MD; Arun Nachiappan, MD; Amit Parulekar, MD.

Brigham and Women's Hospital, Boston, MA: Dawn L. DeMeo, MD, MPH; Craig Hersh, MD, MPH; Francine L. Jacobson, MD, MPH; George Washko, MD.

Columbia University, New York, NY: R. Graham Barr, MD, DrPH; John

Austin, MD; Belinda D'Souza, MD; Gregory D.N. Pearson, MD; Anna

Rozenshtein, MD, MPH, FACR; Byron Thomashow, MD.

Duke University Medical Center, Durham, NC: Neil MacIntyre, Jr., MD; $H$. Page McAdams, MD; Lacey Washington, $M D$.

HealthPartners Research Institute, Minneapolis, MN: Charlene McEvoy, MD, MPH; Joseph Tashjian, MD.

Johns Hopkins University, Baltimore, MD: Robert Wise, MD; Robert Brown, MD; Nadia N. Hansel, MD, MPH; Karen Horton, MD; Allison Lambert, MD, MHS; Nirupama Putcha, MD, MHS.

Los Angeles Biomedical Research Institute at Harbor UCLA Medical Center, Torrance, CA: Richard Casaburi, PhD, MD; Alessandra Adami, PhD; Matthew Budoff, MD; Hans Fischer, MD; Janos Porszasz, MD, $\mathrm{PhD}$; Harry Rossiter, PhD; William Stringer, $M D$.

Michael E. DeBakey VAMC, Houston, TX: Amir Sharafkhaneh, MD, $\mathrm{PhD}$; Charlie Lan, DO.

Minneapolis VA: Christine Wendt, MD; Brian Bell, MD.

Morehouse School of Medicine, Atlanta, GA: Marilyn G. Foreman, MD, MS; Eugene Berkowitz, MD, PhD; Gloria Westney, MD, MS.

National Jewish Health, Denver, CO: Russell Bowler, MD, PhD; David A. Lynch, MB.

Reliant Medical Group, Worcester, MA: Richard Rosiello, MD; David Pace, $M D$.

Temple University, Philadelphia, PA: Gerard Criner, MD; David Ciccolella, MD; Francis Cordova, MD; Chandra Dass, MD; Gilbert D'Alonzo, DO; Parag Desai, MD; Michael Jacobs, PharmD; Steven 
Kelsen, MD, PhD; Victor Kim, MD; A. James Mamary, MD; Nathaniel Marchetti, DO; Aditi Satti, MD; Kartik Shenoy, MD; Robert M. Steiner, MD; Alex Swift, MD; Irene Swift, MD; Maria Elena Vega-Sanchez, MD. University of Alabama, Birmingham, AL: Mark Dransfield, MD; William Bailey, MD; Surya Bhatt, MD; Anand Iyer, MD; Hrudaya Nath, MD; J. Michael Wells, MD.

University of California, San Diego, CA: Joe Ramsdell, MD; Paul Friedman, $M D$; Xavier Soler, MD, PhD; Andrew Yen, $M D$.

University of Iowa, Iowa City, IA: Alejandro P. Comellas, MD; John Newell, Jr., MD; Brad Thompson, MD.

University of Michigan, Ann Arbor, MI: MeiLan K. Han, MD, MS; Ella Kazerooni, MD; Carlos H. Martinez, MD, MPH.

University of Minnesota, Minneapolis, MN: Joanne Billings, MD; Abbie Begnaud, MD; Tadashi Allen, MD.

University of Pittsburgh, Pittsburgh, PA: Frank Sciurba, MD; Jessica Bon, MD; Divay Chandra, MD, MSc; Carl Fuhrman, MD; Joel Weissfeld, $M D, M P H$.

University of Texas Health Science Center at San Antonio, San Antonio, TX: Antonio Anzueto, MD; Sandra Adams, MD; Diego Maselli-Caceres,

MD; Mario E. Ruiz, MD.

Funders: SPIROMICS was supported by contracts from the NIH/NHLBI (HHSN $268200900013 \mathrm{C}$, HHSN268200900014C, HHSN $268200900015 \mathrm{C}$, HHSN268200900016C, HHSN $268200900017 \mathrm{C}$, HHSN $268200900018 \mathrm{C}$, HHSN268200900019C, HHSN268200900020C), which were supplemented by contributions made through the Foundation for the NIH from AstraZeneca; Bellerophon Therapeutics; Boehringer Ingelheim Pharmaceuticals, Inc.; Chiesi Farmaceutici SpA; Forest Research Institute, Inc.; GSK; Grifols Therapeutics, Inc.; Ikaria, Inc.; Nycomed GmbH; Takeda Pharmaceutical Company; Novartis Pharmaceuticals Corporation; Regeneron Pharmaceuticals, Inc.; and Sanofi.

COPDGene was supported by award no. RO1 HL089897 and award no. R01 HL089856 from the National Heart, Lung, and Blood Institute. The content is solely the responsibility of the authors and does not necessarily represent the official views of the National Heart, Lung, and Blood Institute or the National Institutes of Health.

The COPDGene project is also supported by the COPD Foundation through contributions made to an industry advisory board comprising AstraZeneca, Boehringer Ingelheim, GlaxoSmithKline, Novartis, Pfizer, Siemens, and Sunovion.

Prior Presentations: Portions of these data were presented previously in abstract form at the American Thoracic Society 2015 International Conference (AJRCCM 2015;191:A3908).

Corresponding Author: Russell P. Bowler, MD, PhD; National Jewish Health, 1400 Jackson Street, Denver, CO 80206, USA (e-mail: BowlerR@NJHealth.org).

Compliance with Ethical Standards:

Conflict of Interest: The authors declare that they do not have a conflict of interest.

\section{REFERENCES}

1. Goniewicz ML, Knysak J, Gawron M, Kosmider L, Sobczak A, Kurek $\mathbf{J}$, et al. Levels of selected carcinogens and toxicants in vapour from electronic cigarettes. Tob Control. 2014; 23(2):133-9.

2. Caponnetto P, Campagna D, Cibella F, Morjaria JB, Caruso M, Russo C, et al. EffiCiency and Safety of an eLectronic cigAreTte (ECLAT) as tobacco cigarettes substitute: a prospective 12-month randomized control design study. PLoS One. 2013; 8(6):e66317.

3. Bullen C, Howe C, Laugesen M, McRobbie H, Parag V, Williman J, et al. Electronic cigarettes for smoking cessation: a randomised controlled trial. Lancet. 2013; 382 (9905):1629-37.
4. Adriaens K, Van Gucht D, Declerck P, Baeyens F. Effectiveness of the electronic cigarette: An eight-week Flemish study with six-month followup on smoking reduction, craving and experienced benefits and complaints. Int J Environ Res. Public Health. 2014; 11 (11):11220-48.

5. Tseng TY, Ostroff JS, Campo A, Gerard M, Kirchner T, Rotrosen J, et al. A Randomized Trial Comparing the Effect of Nicotine Versus Placebo Electronic Cigarettes on Smoking Reduction Among Young Adult Smokers. Nicotine Tob Res. 2016; 18 (10):1937-43.

6. Ghosh S, Drummond MB. Electronic cigarettes as smoking cessation tool: are we there? Curr Opin Pulm Med. 2016.

7. Kalkhoran S, Glantz SA. E-cigarettes and smoking cessation in realworld and clinical settings: a systematic review and meta-analysis. Lancet Respir Med. 2016; 4(2):116-28.

8. E-cigarette use triples among middle and high school students in just one year. CDC Newsroom: Centers for Disease Control and Prevention; 2015.

9. Farsalinos KE, Poulas K, Voudris V, Le Houezec J. Electronic cigarette use in the European Union: analysis of a representative sample of 27460 Europeans from 28 countries. Addiction. 2016.

10. Regan EA, Hokanson JE, Murphy JR, Make B, Lynch DA, Beaty TH, et al. Genetic epidemiology of COPD (COPDGene) study design. COPD. 2010; 7(1):32-43.

11. Couper D, LaVange LM, Han M, Barr RG, Bleecker E, Hoffman EA, et al. Design of the Subpopulations and Intermediate Outcomes in COPD Study (SPIROMICS). Thorax. 2014; 69(5):491-4.

12. Fabbri LM, Hurd SS, Committee GS. Global Strategy for the Diagnosis, Management and Prevention of COPD: 2003 update. Eur Respir J. 2003; 22(1): $1-2$.

13. Wan ES, Castaldi PJ, Cho MH, Hokanson JE, Regan EA, Make BJ, et al. Epidemiology, genetics, and subtyping of preserved ratio impaired spirometry (PRISm) in COPDGene. Respir Res. 2014; 15:89.

14. Jones PW, Quirk FH, Baveystock CM, Littlejohns P. A selfcomplete measure of health status for chronic airflow limitation. The St. George's Respiratory Questionnaire. Am Rev Respir Dis. 1992; 145(6): 1321-7.

15. Mahler DA, Wells CK. Evaluation of clinical methods for rating dyspnea. Chest. 1988; 93(3):580-6.

16. Kim V, Han MK, Vance GB, Make BJ, Newell JD, Hokanson JE, et al. The chronic bronchitic phenotype of COPD: an analysis of the COPDGene Study. Chest. 2011; 140(3):626-33.

17. Suh-Lailam BB, Haglock-Adler CJ, Carlisle HJ, Ohman T, McMillin GA. Reference interval determination for anabasine: a biomarker of active tobacco use. J Anal Toxicol. 2014; 38(7):416-20.

18. Bowler RP, Kim V, Regan E, Williams AAA, Santorico SA, Make BJ, et al. Prediction of acute respiratory disease in current and former smokers with and without COPD. Chest. 2014; 146(4):941-50.

19. Keene JD, Jacobson S, Kechris K, Kinney GL, Foreman MG, Doerschuk CM, et al. Biomarkers Predictive of Exacerbations in the SPIROMICS and COPDGene Cohorts. Am J Respir Crit Care Med. 2016.

20. Schoenborn CA, Gindi RM. Electronic Cigarette Use Among Adults: United States, 2014. NCHS Data Brief. 2015 (217): 1-8.

21. QuickStats: Cigarette Smoking Status Among Current Adult E-cigarette Users, by Age Group-National Health Interview Survey, United States, 2015. MMWR Morb Mortal Wkly Rep 2016; 2016.

22. Nitzkin JL. The case in favor of E-cigarettes for tobacco harm reduction. Int J Environ Res Public Health. 2014; 11(6):6459-71.

23. Hiemstra PS, Bals R. Basic science of electronic cigarettes: assessment in cell culture and in vivo models. Respir Res. 2016; 17(1):127.

24. Gardiner PS. The African Americanization of menthol cigarette use in the United States. Nicotine Tob Res. 2004; 6 Suppl 1:S55-65.

25. Soule EK, Lopez AA, Guy MC, Cobb CO. Reasons for using flavored liquids among electronic cigarette users: A concept mapping study. Drug Alcohol Depend. 2016; 166:168-76.

26. Kosmider L, Sobczak A, Prokopowicz A, Kurek J, Zaciera M, Knysak $\mathbf{J}$, et al. Cherry-flavoured electronic cigarettes expose users to the inhalation irritant, benzaldehyde. Thorax. 2016; 71(4):376-7.

27. Kreiss K, Gomaa A, Kullman G, Fedan K, Simoes EJ, Enright PL. Clinical bronchiolitis obliterans in workers at a microwave-popcorn plant. N Engl J Med. 2002; 347(5):330-8.

28. Etter JF, Zather E, Svensson S. Analysis of refill liquids for electronic cigarettes. Addiction. 2013; 108(9):1671-9. 